\title{
SHOULD WE ADJUST HEALTH EDUCATION METHODOLOGY TO LOW-EDUCATED EMPLOYEES NEEDS? FINDINGS FROM LATVIA, POLAND, SLOVENIA AND SPAIN
}

\section{ELŻBIETA KORZENIOWSKA, KRZYSZTOF PUCHALSKI, ELIZA GOSZCZYŃSKA, and JACEK PYŻALSKI}

Nofer Institute of Occupational Medicine, Łódź, Poland

National Center for Workplace Health Promotion

\begin{abstract}
Objectives: The presented study explored health beliefs and experiences as well as health education needs of low-educated employees (LEEs) (incomplete primary, primary, lower secondary and basic vocational education) in comparison to those with higher education (secondary and tertiary education) in four European countries: Latvia, Poland, Slovenia and Spain. The main aim was to identify a specificity of low-educated employees (LEEs) by capturing their opinions, experiences, attitudes and needs concerning health education. Material and Methods: The sample consisted of 1691 individuals with the status of an employee (approximately 400 respondents in each of 4 countries participating in the project). The respondents were aged 25-54 (both the control group and the target group consisted in 1/3 of the following age groups: 25-34, 35-44 and 45-54). The respondents were interviewed during the years 2009 and 2010 with a structured questionnaire concerning their health, health behaviours as well as educational needs concerning health education. Results: The study revealed substantial differences in the attitudes of people from this group concerning methodology of health education. LEEs prefer more competitions and campaigns and less written educational materials in comparison to those with higher education. Additionally, they more often perceive a fee, longer time, necessity to take part in a knowledge test and a concern that their health will be checked as factors that can discourage them from taking part in a health training. On the other hand, LEEs can by encouraged to take part in such a training by a media broadcast concerning the event, snacks or lottery during the training, or financial incentives. Conclusions: The results of the study proved the need for specific health education guidelines to conduct health education for low-educated employees. These guidelines should take in account the sources of health education preferred by LEEs as well as the factors that can encourage/discourage their participation in trainings concerning health.
\end{abstract}

Key words:

Health education, Low-educated people, Vulnerable groups, Workplace health promotion

\section{INTRODUCTION}

Broadly understood socio-economic status (SES) has proved to be associated with numerous health-related outcomes. However, analysis of former research data indicates that conceptualizing SES as a combination of dimensions such as educational attainment, income and occupational status provides contradictory findings when particular health-related factors are investigated [1]. Those findings suggest that researchers should rather focus on education level separately to isolate it as a deter-

This work was supported by the EU-funded project entitled "Strengthening transversal competences of low-educated employees concerning their health choices in the context of changing labour market" - LEECH (project number: 142222-LLP-1-2008-1-PLGRUNDTVIG-GMP; grant agreement: 2008-3466/001-001). Manager of grant: Elżbieta Korzeniowska, PhD.

Received: December 6, 2013. Accepted: March 11, 2014.

Corresponding author: J. Pyżalski, Nofer Institute of Occupational Medicine, National Center for Workplace Health Promotion, św. Teresy 8, 91-348 Łódź, Poland (e-mail: whpp@imp.lodz.pl). 
mining factor for health related outcomes. Education seems to act as a distinctive single factor that is rarely compensated by other SES variables such as high income and occupational status of a person [1].

Low education itself is considered to be a significant barrier to personal and social development also when health and health behaviours are concerned. Individuals representing low education levels primarily tend to practise more often unhealthy behaviours (such as smoking, drinking alcohol, unhealthy diet) [2-5]. At the same time, less educated individuals are seldom motivated to attempt healthy activities, such as e.g. physical exercise or regular health check-ups. Accordingly, people from this group asses their health status as poorer than individuals from better educated groups [2]. Moreover, some specific aspects of health are also linked to the educational status accordingly those with lower educational level evaluate their physical fitness as poorer when compared with individuals representing higher educational status. The educational differences in self-rated physical fitness were largely explainable by health behaviours such as tobacco smoking and physical activity [6].

Additionally, they have lower competencies potentially restricting their ability to take proper advantage of both medical care as well as messages concerning health and disease due to low health and limited general literacy [7-9]. In other words, the latter means that less educated individuals represent usually lower health literacy level - that makes them less capable to interpret and understand basic health information as well as effectively use health services [10]. Furthermore, survival from serious health problems is connected to educational status. For instance, such correlations have been proved to be true for prostate cancer that led to death earlier in low-educated individuals [11].

From a broader perspective, such mechanism generates higher costs for the society, including those related to health care and social assistance for people with low educational status. In this perspective, low-educated individuals are perceived as a vulnerable group in the field of health and often in their majority are defined as people representing low health literacy. The issues outlined above are often associated with other social problems experienced by this particular group, such as unemployment, unfavourable working conditions (including financial ones), poverty and, consequently, social exclusion.

Generally, methodology of health education for such vulnerable groups is perceived as one of the key contemporary challenges for public health and one of the crucial competencies that should be represented by public health experts [12]. Unfortunately, it is emphasized in the literature that this need for specific content and forms of health education is not fulfilled effectively. Programs targeted to the general population often do not reach this specific group, sometimes paradoxically aggravating inequalities in health [13].

Specific educational needs of patients from excluded groups (not only the low-educated) have been acknowledged by medical professionals [13-15]. This interest has been raised by research data showing that such patients cannot take advantage of ordinary health-related information and health education provided individually by medical staff. Those findings recently led to preparation of specific guidelines concerning communication and education of patients from vulnerable groups [13]. However, those guidelines referring to specific context of medical communication, mostly at individual level, are not sufficient to be extrapolated to other health education activities in a broader sense.

Thus, tailoring health education to the needs of low-educated individuals needs a thorough exploration of the potentially unique beliefs, rationalizations and motivations of members of such defined group in the field of health as well as educational needs shaped by those factors.

Such diagnosis is particularly important in case of low-educated people functioning in the labour market, since this group's situation has not been explored [16]. Additionally, 
individuals from this group may be potentially reached by well-planned and tailored health education and health promotion programmes that have proved their efficacy in case of general population (particularly people representing better educational status). Still there are not many methodological sources presenting the measures to offer the health education that is tailored to the needs of low-educated people, particularly within workplace health promotion schemes [17].

\section{MATERIAL AND METHODS}

The research data presented in this article has been gathered in the years 2009/2010. The sample consisted of 1691 individuals with the status of an employee (approximately 400 respondents in each of 4 countries: Latvia, Poland, Spain and Slovenia participating in the project.

The sample criteria have been designed so as to best identify a specificity of low-educated employees (LEEs) in comparison to groups with high education status. Therefore, the respondents were stratified into a target group people with low education status, namely with incomplete primary, primary, lower secondary and basic vocational education (levels: 0-2 and 3C, according to ISCED 1997) (but not those who continue their education process), and a control group - people with high level of education, namely with secondary (both general and vocational) or tertiary education (levels: $3 A-B$ and 4-6 according to ISCED1997). The respondents were aged 25-54 (both the control group and the target group consisted in $1 / 3$ of the following age groups: 25-34, 35-44 and 45-54). They were chosen from employees in various branches and inhabitants of both cities (big and small) and rural areas. The respondents have been interviewed with a structured questionnaire concerning their health, health behaviours as well as educational needs concerning health education. The research tool consisted of 39 questions of various kinds. The specific research questions addressed the following main issues:
1. Self-assessment of health knowledge and the need to develop it further.

2. Involvement in healthy behaviours (e.g. physical activity, healthy diet, etc.), and the social barriers to such involvement (e.g. discouraging opinions of other people).

3. Preferred health education activities and the factors that can discourage/encourage the respondents to participate in such activities.

4. The preferred health information sources (e.g. medical staff, lay-people that experienced a particular health problem).

5. Health knowledge test (concerning understanding popular health messages and expressions, e.g. passive smoking, body mass index, etc.).

6. Additionally, information on objective health status as well as material status has been gathered.

The response option were mostly dichotomous $(\mathrm{Y} / \mathrm{N})$ or 5-option scales (totally agree, agree, disagree, totally disagree, hard to say).

In each country the questionnaire has been piloted on the small sample of respondents who met the criteria of a target group in order to ensure understanding of the items. The data presented in the article concern those aspects of measured factors that clearly distinguish the group of LEEs from employees with higher level of education.

\section{Statistics}

Standard $\mathrm{Chi}^{2}$ tests have been used to analyse the data presented in this paper.

\section{RESULTS}

The research data have clearly shown that low-educated employees present less positive attitudes toward healthy lifestyle. More than 1/3 of them (36\%) do not think about health on daily basis and does not care how their behaviours impact their health (compared to $24 \%$ of better educated 
employees, $\mathrm{p}<0.001)$. Only $25 \%$ of LEEs willingly listen to information concerning healthy behaviour and often think how to lead a healthier lifestyle (compared to $42 \%$ of better educated, $\mathrm{p}<0.001$; $\mathrm{Chi}^{2}$ test). It has been also discovered that low-educated employees are less often willing to improve their health through healhy lifestyle. To be more specific, one may observe than the lower the education level is, the less often respondents try to limit sugar and fat consumption or improve their physical fitness. They also less often undertake medical check-ups to prevent diseases.

LEEs significantly less often understand which health conditions (e.g. LDL cholesterol) adversely affect their health and less often understand the meaning of common expressions used in health education (e.g. passive smoking, disease prevention: $27 \%$ of employees with elementary education present lack of understanding of those terms, compared with only $3 \%$ of those with higher education). Taking those data into account, the health education targeted to the group of LEEs seems to be a significant challenge that calls for specific measures and strategies.

It is worth noting that the preferences concerning needs for health education in LEEs' differ from those of better educated employees. Figure 1 presents comparative data on 3 issues: preferred sources of health knowledge and skills as well as the factors that, according to respondents, would encourage or discourage them to take part in health education training. In each case, specific items have been grouped based on the fact that they have been less, more or to the same extent preferred by LEEs, compared to well-educated employees ( $p<0.001$; Chi $^{2}$ test). Those comparisons clearly indicate the need to tailor health education methodology to the specific situation of LEEs.

\section{DISCUSSION AND CONCLUSION}

The gathered data clearly confirms the previous findings [2-4] indicating that low-educated individuals, due to specific beliefs, motivations and behaviours that exert generally adverse effect on their health, should be a significant target group for health education activities.

However, those activities, in order to be effective, must reflect the specific educational needs of this group, since the data confirmed the existence of numerous potential constraints that may result in ineffectiveness of health education projects addressed to low-educated employees. Namely, health education organizers should avoid using such information sources as paper media (help books, newspaper magazines, or the new media, e.g. Internet). Those constraints reflect well known limitations, which stem from general lower literacy of individuals at lower educational levels [18,19].

Instead of measures specified above, it is better to use such methods as competitions or campaigns on health issues. When health education is utilized by health trainings/workshops it is worth to consider that there is a list of factors that are more likely to discourage LEEs from participation. Actually there are 2 kinds of such factors: financial (e.g. fee) and those connected with the content and methodology of the training (e.g. too difficult terminology, health check during the training). The health education organizer who is aware of such challenges may prepare and implement the program that targets them. Finally, there are factors that encourage LEEs more to participate in a health training. Some of them are inexpensive "gifts" such as snacks during the trainings, the lottery or a payment for taking part. Utilization of such methods is worth considering since they are not very costly and can substantially improve participation, engagement and effectiveness of health trainings for LEEs. It is worth underlying that failing to address the specific needs of low-educated individuals in the society may lead to adverse effects due to magnifying health inequalities among people with different educational levels. This approach is clearly in line with measures advised for other vulnerable groups, e.g. elderly people (particularly considering the ageing of the population in Europe). Health 


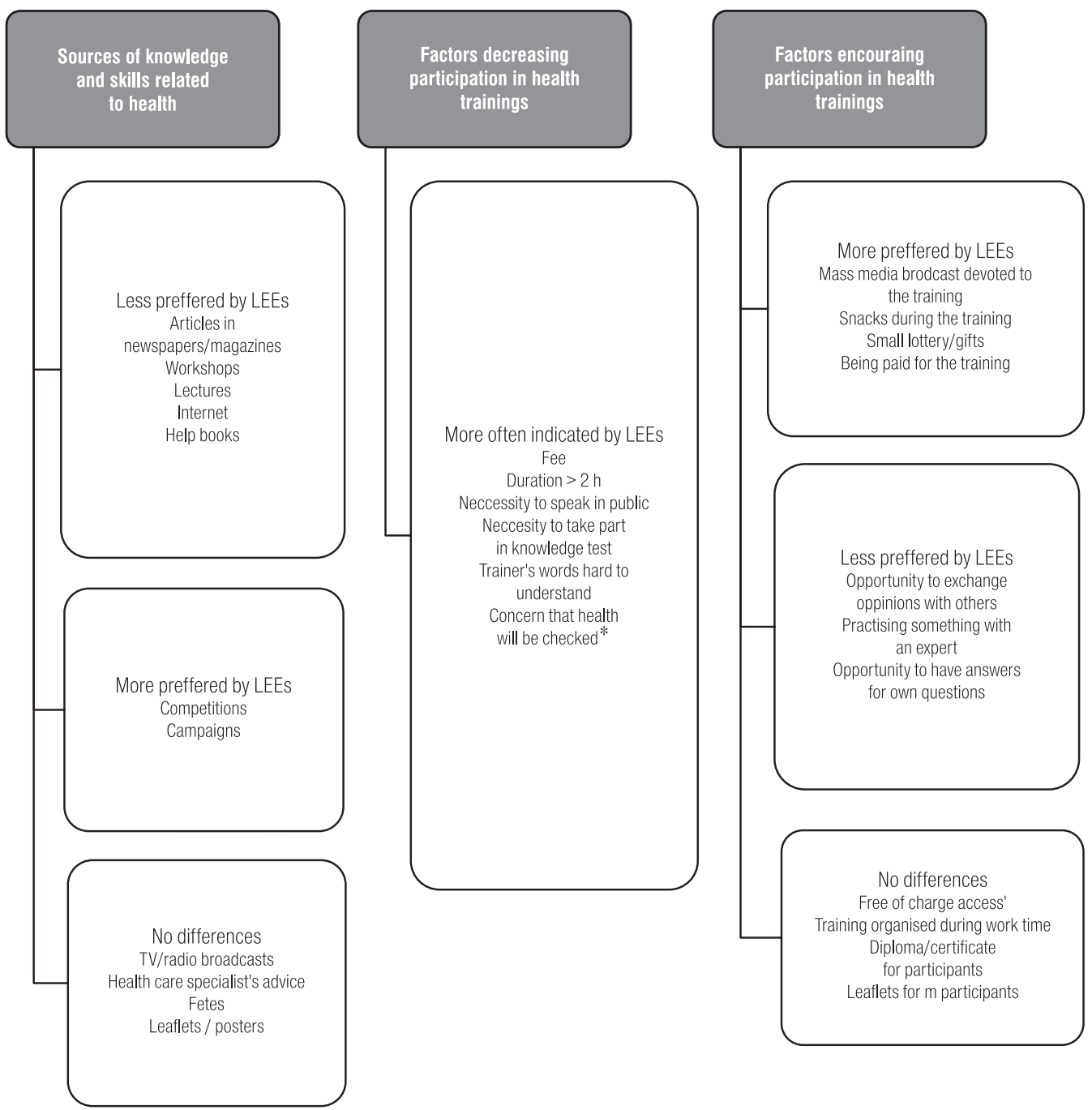

* In all included items LEEs answers were more prevalent.

All the differences: $\mathrm{p}<0.001$.

Fig. 1. Model of health education needs in less educated employees (in comparison to well educated)

literacy and lifelong learning are a part of a new paradigm of societal answer to psychosocial problems experienced by this group [20,21].

\section{REFERENCES}

1. Nocon M, Keil T, Willich N. Edcuation, income, occupational status and health risk behavior. J Public Health. 2007;15:401-5, http://dx.doi.org/10.1007/s10389007-0120-6.
2. Goszczyńska E. Low education as a social problem in the European Union. In: Korzeniowska E, Puchalski K, editors. The low educated employees towards health - challenges for health education. Riga: Institute of Occupational Safety and Environmental Health; 2010, p. 9-25.

3. Idris BI, Giskes K, Borrell C, Benach J, Costa G, Federico B, et al. Higher smoking prevalence in urban compared to nonurban areas: Time trends in six European countries. Health Place. 2007;13(3):702-12, http://dx.doi.org/10.1016/j.healthplace.2006.11.001. 
4. Korzeniowska E. [Level of education in health sociology research - changes, phenomena and interpretation dilemas]. In: Bąk A, Kubisz-Muła $Ł$, editors. [Methods, techniques and practice in social science research]. BielskoBiała: Wydawnictwo Akademii Techniczno-Humanistycznej w Bielsku-Białej; 1999. p. 129-47. Polish.

5. Pampel FC, Denney JT. Cross-national sources of health inequality: Education and tobacco use in the world health survey. Demography. 2011;48:653-74, http://dx.doi.org/10.1007/ s13524-011-0027-2.

6. Pulkkinen KR, Mäkinen T, Valkeinen H, Prättälä R, Borodulin K. Educational differences in self-rated physical fitness among Finns. BMC Pub Health. 2013 [cited 2013 Nov 3];13:163. Available from: http://www.biomedcentral. com/1471-2458/13/163.

7. Marmot M, Wilkinson RG. Social determinants of health. Oxford: Oxford University Press; 2005, http://dx.doi. org/10.1093/acprof:oso/9780198565895.001.0001.

8. European Commission. Health and food. Spec Eurobarometer. 2006;246/64.3.

9. European Commission. Sport and Managed Care Outlook. Partnership for Clear Health Communication Works to Improve Health Literacy. 2007;20(8).

10. Chinn D. Critical health literacy: A review and critical analysis. Soc Sci Med. 2011;73(1):60-7, http://dx.doi.org/10.1016/ j.socscimed.2011.04.004.

11. Aarts MJ, Kamphuis CBM, Louwman MJ, Coebergh JWW, Mackenbach JP, Lenthe van FJ. Educational inequalities in cancer survival: A role for comorbidities and health behaviours? J Epidemiol Community Health. 2013;67:365-73, http://dx.doi.org/10.1136/jech-2012-201404.

12. Petrakova A, Sadana R. Problems and progress in public health education. Bull World Health Organ. 2007;85: 963-70, http://dx.doi.org/10.2471/BLT.07.046110.
13. European Commission. Managed Care Outlook. Partnership for clear health communication works to improve health literacy. 2007;8.

14. Schyve PM. Language differences as a barrier to quality and safety in health care: The joint commission perspective. J Gen Int Med. 2007;22:360-1, http://dx.doi.org/10.1007/ s11606-007-0365-3.

15. Schwartzberg JG. Low health literacy. What do your patients really understand? Nurs Econom. 2002;3:1-3.

16. Steinbrunn RL. Blue collar workers: what factors influence participation in health education programmes. Benefits Q. 1988;4:71-9.

17. Korzeniowska E, Puchalski K, editors. The low educated employees towards health - challenges for health education. Riga: Institute of Occupational Safety and Environmental Health; 2010.

18. Minelli M, Breckon DJ. Community health education, settings, roles and skills. Sudbery: Jones and Bartlett Publishers International; 2009.

19. Korzeniowska E, Puchalski K. [Employees health education - challenges according to educational level]. Med Pr. 2012;63(1):55-71. Polish.

20. European Union. European year of active aging and solidarity between generations. 2012 [cited 2014 Jan 23]. Available from: http:/www.cor.europa.eu/en/events/forums/Documents/ proceedingsEY2012.pdf.

21. Ahtonen A. Active and healthy ageing - can EU deliver? European Policy Centre, Feb 2011. Available from: http:// www.epc.eu/documents/uploads/pub_1235_active_and_ healthy_ageing.pdf.

This work is available in Open Access model and licensed under a Creative Commons Attribution-NonCommercial 3.0 Poland License - http://creativecommons.org/ licenses/by-nc/3.0/pl/deed.en. 